\title{
Property of electrospinning silk fibroin nanofibers prepared by different dissolved methods
}

\author{
Huiying $\mathrm{WU}^{\mathrm{a}, *}$, Yan $\mathrm{ZHOU}^{\mathrm{b}}$, Ping $\mathrm{YAO}^{\mathrm{c}}$, Maomao $\mathrm{DING}^{\mathrm{D}}$ \\ Suzhou Institute of Trade \& Commerce, Suzhou 215009, China \\ a why_1220@sina.com, ${ }^{\mathrm{b}}$ gwxzygjf@163.com, ${ }^{\mathrm{c}}$ pyao@szjm.edu.cn, ${ }^{\mathrm{d}} 422621424 @ q q . c o m$
}

\begin{abstract}
In the present study, silk was dissolved in $\mathrm{CaCl}_{2}$-formic acid and $\mathrm{CaCl}_{2}-\mathrm{C}_{2} \mathrm{H}_{5} \mathrm{OH}-\mathrm{H}_{2} \mathrm{O}$ to obtain silk fibroin solution. The dissolve process, morphology, structure and mechanical properties of nanofibers prepared by electrospinning were studied. It showed that nanofibril structures were exhibited in the silk fibroin solution in $\mathrm{CaCl}_{2}$-formic acid compared with traditional method dissolving in $\mathrm{CaCl}_{2}-\mathrm{C}_{2} \mathrm{H}_{5} \mathrm{OH}-\mathrm{H}_{2} \mathrm{O}$ solution, and the viscosity of the solution was much higher. The average diameter of nanofibers prepared by $\mathrm{CaCl}_{2}$-formic acid dissolution method was $375 \pm 26 \mathrm{~nm}$, and it showed well drawability, after stretching to 1 times, its breaking strength and elongation at break reaching $18.6 \pm 3.8 \mathrm{MPa}$ and $14.0 \pm 2.5 \%$, respectively, was improved obviously relative to nanofibers prepared by $\mathrm{CaCl}_{2}-\mathrm{C}_{2} \mathrm{H}_{5} \mathrm{OH}-\mathrm{H}_{2} \mathrm{O}$ dissolution method. It demonstrated that the good mechanical property of fibers was contributed to the fibrillar structures in the solution.
\end{abstract}

\section{Introduction}

Natural silk from the silkworm, Bombyx mori, has been used as biomedical suture material for centuries[1]. Silk fibroin is a nature protein and is known to promote cell attachment and proliferation and tissue regeneration. It has been reported that the biological features of silk fibroin make it a very good choice for use as regeneration [2,3]. Silk fibroin has been widely explored in many biomedical applications due to its impressive biocompatibility, biodegradability, minimal inflammatory reactions $[4,5]$. Electrospinning is a unique method capable of producing nanoscale fibers from both synthetic as well as natural polymers for biomedical applications [6,7]. The cylinder collector rotating at high speed can obtain aligned fiber was a simple and common way relative to other methods to obtain aligned fiber[8]. However, if the speed of collector was too higher, the fibers were easily to fracture.

In the present study, silk was dissolved in $\mathrm{CaCl}_{2}$-formic acid and $\mathrm{CaCl}_{2}-\mathrm{C}_{2} \mathrm{H}_{5} \mathrm{OH}-\mathrm{H}_{2} \mathrm{O}$ to obtain silk fibroin solution. To obtain aligned and well mechanical properties electrospun silk fibroin nanofibers, we achieve an optimal combination of the revolve cylinder as equipment collector and physical stretching with the speed of 1000rpm. To compare the

*Corresponding authors: why_1220@sina.com (WU Huiying) 
different properties of nanofibers prepared by different dissolved methods, the dissolve process, morphology, structure and mechanical properties of nanofibers prepared by electrospinning were studied.

\section{Materials And Methods}

\subsection{Preparation of SF Regenerated Films}

$\mathrm{CaCl}_{2}$ - formic acid dissolved method: Raw silk fibers were degummed twice with $0.05 \%(\mathrm{w} / \mathrm{w}) \mathrm{Na}_{2} \mathrm{CO}_{3}$ solution at $100^{\circ} \mathrm{C}$ for $30 \mathrm{~min}$ and then rinsed thoroughly with deionized water for three times to remove glue-like sericin proteins. The degummed silk fibroin(SF) was dissolved in a mixture of solvents composed of $\mathrm{CaCl}_{2}$ : formic acid $=5: 95(\mathrm{w} / \mathrm{w})$ for $2 \mathrm{~h}$ under room temperature. The SF membrane was prepared by spread the SF solution on the polyethylene plastic board and dried under the room temperature, was named SF1 films.

$\mathrm{CaCl}_{2}-\mathrm{C}_{2} \mathrm{H}_{5} \mathrm{OH}-\mathrm{H}_{2} \mathrm{O}$ dissolved method: Raw silk fibers were degummed twice with $0.05 \%(\mathrm{w} / \mathrm{w}) \mathrm{Na}_{2} \mathrm{CO}_{3}$ solution at $100^{\circ} \mathrm{C}$ for $30 \mathrm{~min}$ and then rinsed thoroughly with deionized water for three times to remove glue-like sericin proteins. The degummed SF was dissolved in a mixture of solvents composed of $\mathrm{CaCl}_{2}: \mathrm{C}_{2} \mathrm{H}_{5} \mathrm{OH}: \mathrm{H}_{2} \mathrm{O}=44: 45: 11(\mathrm{w} / \mathrm{w})$ for $6 \mathrm{~h}$ at $80^{\circ} \mathrm{C}$. The solution was then dialyzed in cellulose tubular membrane (molecular cutoff $=$ $8000 \sim 14000$, Sigma, USA) against distilled water for 3 days. The water was changed every $2 \mathrm{~h}$. The SF solution was filtered and air-dried to obtain the regenerated SF films, was named SF2 films. Desalt treatment in deionized water for 3-4h and air-dried to obtain the regenerated SF2 films.

\subsection{Electrospinning and Post-Treatment}

The $8 \%$ SF electrospinning solution was prepared by dissolving regenerated SF1 and SF2 films in $98 \%$ formic acid for 1 and $3 \mathrm{~h}$, respectively. In the electrospinning process, the SF solutions were placed into the syringe with a stainless needle connected to the high voltage power supplier, a voltage of $12 \mathrm{kV}$ was applied to the stainless needle and a distance of $10 \mathrm{~cm}$ between the syringe tip was employed. High voltage power supply (DW-P503-4AC, Dongwen High Voltage Power Tianjin Power Supply Plant, China), a syringe pump (WZ-50C66 T, Medical Instrument Corporation of Zhejiang University, Zhejiang, China). Cylinder collector(manmade), the rotation speed of the collector was studied at speed of $1000 \mathrm{rpm}$.

All electrospinning experiments were performed with the same processing conditions. As the voltage increases, a drop of SF solution formed at the tip of the needle, and then a jet was ejected. With the solvent evaporating, the SF nanofibers formed on the collection screen. Then ethanol treatment of SF nanofibers were immersed in 75/25 (v/v) ethanol/water for $30 \mathrm{~min}$ to induce crystallization of SF, and then dried in vacuum at room temperature for $24 \mathrm{~h}$. The nanofibers prepared by different dissolved method were named $\mathrm{SF}-\mathrm{CaCl}_{2}$-formic acid and SF- $\mathrm{CaCl}_{2}-\mathrm{C}_{2} \mathrm{H}_{5} \mathrm{OH}-\mathrm{H}_{2} \mathrm{O}$, respectively.

\subsection{Characterizing Techniques}

The morphology of SF nanofibers were observed using SEM (S-5700, Hitachi, Tokyo, Japan). Samples were mounted on copper plate and sputter-coated with gold layer $20-30 \mathrm{~nm}$ thick prior to imaging. The diameters of the fibers were acquired from randomly collected 
SEM images and measured by Image J. For each sample, the average fiber diameter and distribution were determined based on 100 random measurements.

Rheological studies were run on a rheometer (Rheometer, TA Instruments, New Castle, DE) with a $35 \mathrm{~mm}$ cone plate. The normal force applied on the sample during lowering of the top plate was limited to $0.1 \mathrm{~N}$. The shear rate was linearly increased from 0.1 to $5000 \mathrm{l} / \mathrm{s}$ at $25^{\circ} \mathrm{C}$.

Mechanical properties of samples were determined by a Universal Testing Machine (model 3365, Instron corp., Canton, MA, USA) at $20^{\circ} \mathrm{C}$, and $65 \% \mathrm{RH}$. Various parameters were set as follows: force accuracy, $1 \mathrm{cN}$; and elongation accuracy, $0.01 \mathrm{~mm}$. Strips measuring $50 \times 10 \mathrm{~mm}$ were glued on a paper frame and then mounted on Instron tensile tester. The sample was broke by elongation rate $20 \mathrm{~mm} / \mathrm{min}$ with a gauge length of $20 \mathrm{~mm}$. Average tensile properties from five specimens were measured.

\section{Results And Discussion}

\subsection{Morphology and Viscosity of SF solution}

In this work, a novel dissolve method for producing fibers from a $\mathrm{CaCl}_{2}$ - formic acid solution, hierarchical fibrillar structures were exhibited in the solution, as showed in Fig.1(A). The viscosity of solution was showed in Fig.1(B), the viscosity was higher compared with traditional method dissolving in $\mathrm{CaCl}_{2}-\mathrm{C}_{2} \mathrm{H}_{5} \mathrm{OH}-\mathrm{H}_{2} \mathrm{O}$ solution, and was able to satisfy the electrospinning process.
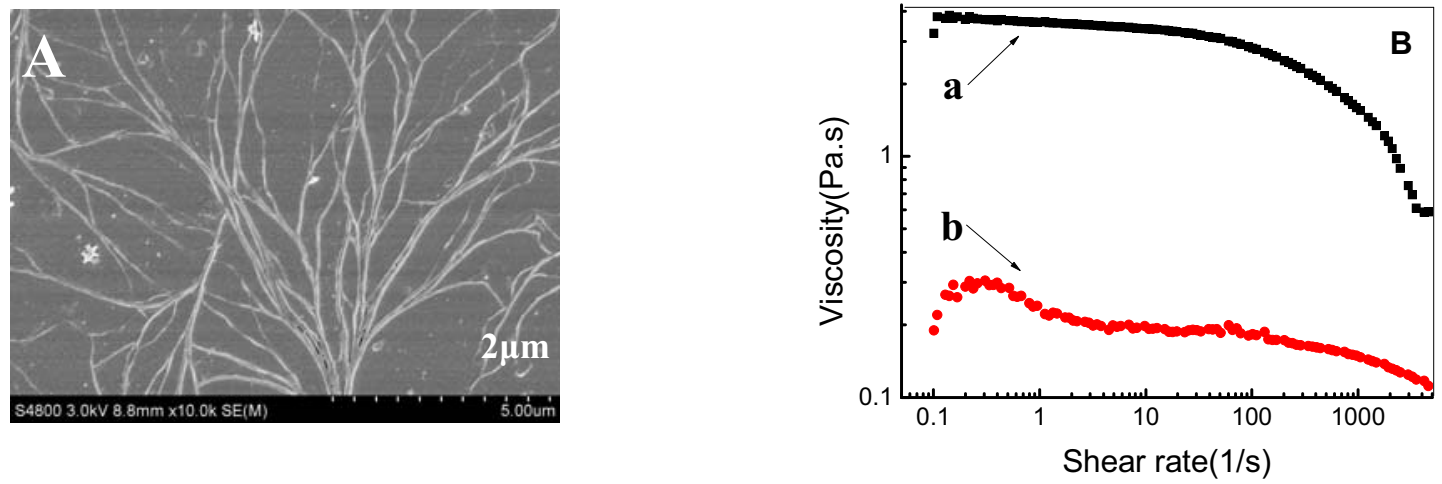

Fig.1 Morphology(A. $\mathrm{CaCl}_{2}$ - formic acid solution), Viscosity(B) of SF solution: a. $\mathrm{CaCl}_{2}$ - formic acid solution; b. $\mathrm{CaCl}_{2}-\mathrm{C}_{2} \mathrm{H}_{5} \mathrm{OH}-\mathrm{H}_{2} \mathrm{O}$ solution.

\subsection{Morphology of SF Nanofibers}

The morphology of SF nanofibers was varied with different dissolved method in the same parameters, as showed in Fig.2. The average diameter of nanofibers prepared by $\mathrm{CaCl}_{2}$-formic acid dissolution method was $375 \pm 26 \mathrm{~nm}$, which much higher than $\mathrm{SF}-\mathrm{CaCl}_{2}-\mathrm{C}_{2} \mathrm{H}_{5} \mathrm{OH}-\mathrm{H}_{2} \mathrm{O}$ with diameter of $132 \pm 15 \mathrm{~nm}$. The $\mathrm{SF}-\mathrm{CaCl}_{2}-\mathrm{C}_{2} \mathrm{H}_{5} \mathrm{OH}-\mathrm{H}_{2} \mathrm{O}$ was more uniform and smooth. After stretching, the majority fibers were oriented along the longitudinal axis to form a unique aligned structure, while, $\mathrm{SF}-\mathrm{CaCl}_{2}-\mathrm{C}_{2} \mathrm{H}_{5} \mathrm{OH}-\mathrm{H}_{2} \mathrm{O}$ showed uneven thickness along the fibers, as showed in Fig.3. 


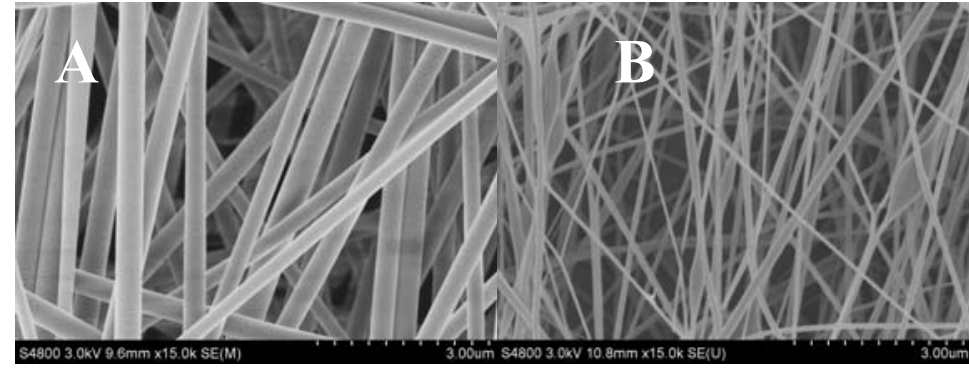

Fig.2 Morphologies of SF nanofibers: A. SF- $\mathrm{CaCl}_{2}$ - formic acid, $375 \pm 26 \mathrm{~nm}$; B. $\mathrm{SF}-\mathrm{CaCl}_{2}-\mathrm{C}_{2} \mathrm{~J}_{5} \mathrm{OH}-\mathrm{H}_{2} \mathrm{O}, 132 \pm 15 \mathrm{~nm}$.

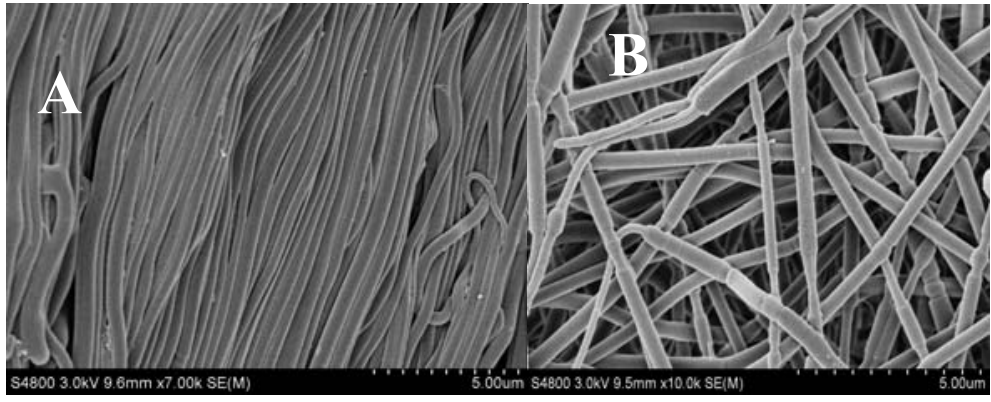

Fig.3 Morphologies of SF nanofitines after stretching: A. SF-CaCl 2 - formic acid; B.

$$
\text { SF- }-\mathrm{CaCl}_{2}-\mathrm{C}_{2} \mathrm{H}_{5} \mathrm{OH}-\mathrm{H}_{2} \mathrm{O} \text {. }
$$

\subsection{Mechanical Property}

The mechanical properties of electrospun SF nanofibers were tested, since it was a key factor for applications in tissue engineering. According to the results of mechanical property test, as showed in Table1, the mechanical properties of $\mathrm{SF}-\mathrm{CaCl}_{2}$-formic acid were much higher than $\mathrm{SF}-\mathrm{CaCl}_{2}-\mathrm{C}_{2} \mathrm{H}_{5} \mathrm{OH}-\mathrm{H}_{2} \mathrm{O}$. The stress of $\mathrm{SF}-\mathrm{CaCl}_{2}-$ formic acid was nearly 4 times to nanofibers obtained by the traditional dissolved method[9]. Therefore, it is believed that the improvement of the mechanical properties of $\mathrm{SF}-\mathrm{CaCl}_{2}-\mathrm{C}_{2} \mathrm{H}_{5} \mathrm{OH}-\mathrm{H}_{2} \mathrm{O}$, was likely due to the preserved nanofibrils in electrospinning solutions. Above all, to improve the mechanical property of fibers, post-drawing was applied on the fibers. After 1 times stretching, the breaking strength and elongation at break reaching $18.6 \pm 3.8 \mathrm{MPa}$ and $14.0 \pm 2.5 \%$.

Table 1 Mechanical properties of silk fibroin nanofibers

\begin{tabular}{cccc}
\hline Dissolved solution & Drawing times & Stress $(\mathrm{MPa})$ & Strain at break $(\%)$ \\
\hline & 0 & $12.5 \pm 2.3$ & $16.8 \pm 3.4$ \\
$\mathrm{CaCl}_{2}$ - formic acid & 0.5 & $14.6 \pm 1.4$ & $15.2 \pm 4.2$ \\
& 1 & $18.6 \pm 3.8$ & $14.0 \pm 2.5$ \\
$\mathrm{CaCl}_{2}-\mathrm{C}_{2} \mathrm{H}_{5} \mathrm{OH}-\mathrm{H}_{2} \mathrm{O}$ & 0 & $3.6 \pm 1.5$ & $4.8 \pm 2.3$ \\
& 0.5 & $4.8 \pm 2.6$ & $3.2 \pm 1.7$ \\
\hline
\end{tabular}




\section{Conclusion}

In this paper, a novel method for dissolving degummed silk in $\mathrm{CaCl}_{2}$-formic acid system was applied, and hierarchical nanofibril structures were exhibited in the solution compared with traditional method dissolving in $\mathrm{CaCl}_{2}-\mathrm{C}_{2} \mathrm{H}_{5} \mathrm{OH}-\mathrm{H}_{2} \mathrm{O}$ solution, and the viscosity of the solution was higher. Silk was dissolved in $\mathrm{CaCl}_{2}$-formic acid and $\mathrm{CaCl}_{2}-\mathrm{C}_{2} \mathrm{H}_{5} \mathrm{OH}-\mathrm{H}_{2} \mathrm{O}$ to obtain SF solutions. The dissolve process, morphology, structure and mechanical properties of nanofibers prepared by electrospinning were studied. It showed that nanofibril structures were exhibited in the SF solution in $\mathrm{CaCl}_{2}$-formic acid compared with traditional method dissolving in $\mathrm{CaCl}_{2}-\mathrm{C}_{2} \mathrm{H}_{5} \mathrm{OH}-\mathrm{H}_{2} \mathrm{O}$ solution, and the viscosity of the solution was much higher. The average diameter of nanofibers prepared by $\mathrm{CaCl}_{2}$-formic acid dissolution method was $375 \pm 26 \mathrm{~nm}$, and it showed well drawability, after stretching to 1 times, its breaking strength and elongation at break reaching $18.6 \pm 3.8 \mathrm{MPa}$ and $14.0 \pm 2.5 \%$, respectively.

\section{Acknowledgments}

This research was financially supported by the Jiangsu Province applied basic research program (Natural Science Foundation) (BK20141207), Suzhou City applied basic research projects (industrial sector) (SYG201431), China Textile Industry Association Technology guidance project (2015009), Suzhou Institute of Trade \& Commerce project (KY-ZR1501) and National Special Foundation of Cocoon Silk Devlopment Project 2015( The Development and Industrialization of Digital Printing Composite Functional Silk Products).

\section{References}

1. S.N. Fan, Y.P. Zhang, H.L. Shao, et al. Electrospun regenerated silk fibroin mats with enhanced mechanical properties[J]. International Journal of Biological Macromolecules, 2013, 56: 83-88.

2. B. Kundu, N.E. Kurland, S. Bano, et al. Silk proteins for biomedical applications: bioengineering perspectives[J]. Progress in Polymer Science, 2014, 39: 251-267.

3. C. Vepari, D.L. Kaplan. Silk as a biomaterial[J]. Progress in Polymer Science, 2007, 32(8-9): 991-1007.

4. M.F. Zhu, K. Wang, J.J. Mei, et al. Fabrication of highly interconnected porous silk fibroin scaffolds for potential use as vascular grafts[J]. Acta Biomaterialia, 2014, 10(5): 2014-2023.

5. C.S. Ki, S.Y. Park, H.J. Kim, et al. Development of 3-D nanofibrous fibroin scaffold with high porosity by electrospinning: implications for bone regeneration[J]. Biotechnol Letter, 2008, 30: 405-410.

6. J. Ayutsede, M. Gandhi, S. Sukigara, et al. Regeneration of Bombyx mori silk by electrospinning. Part 3: characterization of electrospun nonwoven mat[J]. Polymer, 2005, 46(5): 1625-1634.

7. Z. Liu, F. Zhang, J.F. Ming, et al. Preparation of Electrospun Silk Fibroin Nanofibers from Solutions Containing Native Silk Fibers[J]. Applied Polymer, 2014, 41236: 1-7.

8. P. Katta, M. Alessandro, R.D. Ramsier, et al. Continuous electrospinning of aligned polymer nanofibers onto a wire drum collector[J]. Nano Letters, 2004, 4(11): 2215-2218. 